\title{
In vitro Investigations of Cumin Oil as Antioxidants Agent on Fresh and Fried Edible Oil
}

\author{
Faroug Bakheit Mohamed Ahmed \\ Department of Biochemistry, Faculty of Science and Technology, Shendi University, Shendi, Sudan
}

Email address:

farougmhmd@gmail.com

\section{To cite this article:}

Faroug Bakheit Mohamed Ahmed. In vitro Investigations of Cumin Oil as Antioxidants Agent on Fresh and Fried Edible Oil. International Journal of Food Engineering and Technology. Vol. 2, No. 1, 2018, pp. 1-9. doi: 10.11648/j.ijfet.20180201.11

Received: May 7, 2018; Accepted: May 31, 2018; Published: July 30, 2018

\begin{abstract}
This study was designed to determine the effect of cumin oil as antioxidant on the chemical properties of stored sunflower oil. The study is complementary to a previous study in which cumin oil was used to demonstrate its effect on fried sunflower oil. Two samples of sunflower oil were subjected to chemical tests before and after the addition of cumin oil. In addition, four equal samples in volume of sunflower oil were prepared and then the following steps were made, nothing on the first sample, the second sample was transformed into a water bath at the boiling point for 20 min, to the third sample cumin oil added, and in the fourth both process addition and boiling occurred. Also two of fried sun flower oil of taameia and fish was prepared in the same above volume after purification and filtration, after that to both samples cumin oil was added separately. The six samples were then transferred to a storage environment similar to that in the local market in Shendi area for a period of time from 10 October 2017 to 10 April 2018. At the end of storage the samples were investigated to assess their chemical properties. The results showed a difference in the values of the properties, where there was a clear decrease in the values of peroxide and acidity, while an increase in the saponification value was observed and this may be attributed to antioxidant compounds in cumin oil, reaction between hydroxyl group compounds of cumin with acid groups of sample oil which lead to decline carboxyl groups in oil, and could be due to increase of ester formation result from previous reactions respectively for three chemical properties. In addition, the investigations resulted in a clear reduction in the peroxide value of the mixtures oil compared with pure sunflower oil and unexpectedly for the temperature, the boiling of fresh and mixture oil before storage had appeared a decrease in peroxide value.
\end{abstract}

Keywords: Cumin, Spices, Antioxidant, Peroxide, Saponification, Taameia

\section{Introduction}

Oxidation of fats and oils is an important indicator for performance and shelf life of oils [1]. The oxidation process is complex, dependent on the light intensity and temperature. In the first stage it is formed hydro peroxides, peroxides, and then polymers of peroxides [2]. Oxidative stability of oils is the resistance to oxidation during processing and storage [3]. Resistance to oxidation can be expressed as the period of time necessary to attain the critical point of oxidation, whether it is a sensorial change or a sudden acceleration of the oxidative process [4]. Oxidative stability is an important indicator to determine oil quality and shelf life [5] because low-molecular-weight off-flavor compounds are produced during oxidation. The off-flavor compounds make oil less acceptable or unacceptable to consumers or for industrial use as a food ingredient. Oxidation of oil also destroys essential fatty acids and produces toxic compounds and oxidized polymers. Oxidation of oil is very important in terms of palatability, nutritional quality, and toxicity of edible oils.

An antioxidant is any substance, present at low concentrations compared to oxidizable substrate; significantly preventing or delaying the oxidation of the substrates [6]. Food antioxidant is specially formulated to prevent or retard oxidation of oxidizable materials such as fats [7]. Free radicals produced by oxidation reactions can start chain reactions that lead to further oxidation by chain reaction. Antioxidants terminate these chain reactions by removing free radical intermediates and inhibit other oxidation reactions by themselves being oxidized [8]. Antioxidants act as "free radical scavengers" and thereby prevent damage done by these free radicals. Food components such as lipids are very susceptible to oxidation, which results in detrimental changes to the color, odor and 
nutritive value of the food products. Antioxidants prevent such changes by retarding or slowing down the process of oxidation or rancidity [9].

The peroxide value (PV) is applicable for monitoring the formation of peroxides in the early stages of oxidation. During oxidation the peroxide value may reach a maximum and then decreases [10]. Variations of peroxide value can arise from different factors such as the degree of unsaturation of the fatty acids present in the particular oil, storage, exposure to light, and the content of metals or other compounds that may catalyze the oxidation processes [11]. Recommended limits that have been set for the quality oils are: peroxide value less than 3 when the oil leaves the factory, less than 5 after the bottle it's open and less than 10 in use. Generally, the values are substantially lower than that. $\mathrm{PV}$ is used only in the case of oil that is not rancid [12].

The saponification value (SV) is the number of $\mathrm{mg}$ of potassium hydroxide required to saponify 1 gram of oil/fat. The saponification value is an index of mean molecular weight of the fatty acids of glycerides comprising a fat. Lower the saponification value, larger the molecular weight of fatty acids in the glycerides and vice-versa. Kirk and Sawyer [13], reported that high saponification values of fats and oils are due to the predominantly high proportion of shorter carbon chain lengths of the fatty acids. Higher saponification value for triglyceride indicates higher medium chain fatty acids [14]. Saponification values have been reported to be inversely related to the average molecular weight of the fatty acids in the oil fractions [15]. In combination with acid values; saponification values are useful in providing information as to the quantity, type of glycerides and mean weight of the acid in a given sample. The saponification value of oils is of interest if the oil is going to be used for industrial purposes [16].

The acid value (AV) is defined as the number of milligrams of potassium hydroxide required to neutralize the free fatty acids present in one gram of fat. It is a relative measure of rancidity as free fatty acids are normally formed during decomposition of oil glycerides. The value is also expressed as per cent of free fatty acids calculated as oleic acid [17]. Acid value of oil is defined as the number of milligrams of potassium hydroxide required to neutralize the free fatty acid in $1 \mathrm{~g}$ of sample and the results is often expressed as the percentage of free fatty acids. It can be determined by directly titrating the oil material in an alcoholic medium with aqueous sodium or potassium hydroxide solution. Cooking oils can undergo either hydrolytic or oxidative rancidity. Acid value is also explained as a measure of the extent to which glycerides in the cooking oil are decomposed by lipase enzyme (hydrolytic rancidity) or by the action of heat or light which is accompanied by the formation of free fatty acid [18]. Vegetable oils are produced from plant seeds, commonly used for frying, baking and other types of cooking. Acidity is a measure of the extent to which vegetable cooking oil has been decomposed by action of light and other action of oxygen, heat, water and other impurities like heavy metals, lead and copper. The decomposition of vegetable cooking oil brings about rancidity that means the vegetable cooking oil having unpleasant smell, taste or flavor. Rancidity is the process by which a substance to become having a rank, unpleasant smell or taste [19]. The free fatty acids (FFA) released during the rancidity process can smell unpleasant and allow free radical to form in the human diet, harming body cells and increase the risk of degenerating diseases such as Cancer, Diabetes, Alzheimer's diseases and Atherosclerosis, a condition in which artery walls thicken due to build up of fatty materials [20]

Spices are an important bionutrients for both food ingredients and nutritional supplement. From ancient times, spices have been used as food additives to enhance the taste and be flavor of food [21]. The term 'spice' originated from the Latin word 'species', meaning of specific kind. A closely related term, 'herb', is used to distinguish plant parts finding the same uses but derived from leafy or soft flowering parts [22]. The essential oils in spices are generally composed of hydrocarbons (terpene derivatives) or terpenes (e.g., $\alpha$ terpinene, $\alpha$-pinene, camphene, limonene, phellandrene, myrcene, and sabinene), oxygenated derivatives of hydrocarbons (e.g., linalool, citronellol, geraniol, carveol, menthol, borneol, fenchone, tumerone, and nerol), benzene compounds (alcohols, acids, phenols, esters, and lactones) and nitrogen- or sulfur-containing compounds (indole, hydrogen sulfide, methyl propyl disulfide, and sinapine hydrogen sulfate) [23]. The ratio of volatiles to non volatiles varies among spices causing flavor similarities and differences within a genus and even within a variety [24].

The scientific name of Cuminum cyminum L. (cumin) referred to as Cuminum odorum Salisb and belonging to the Apiaceae family. The Apiaceae family is a collection of typically aromatic plants having hollow stems and the well known members of this family are anise, asafoetida, caraway, carrot, celery, coriander, cumin, dill, fennel, parsley, parsnip, and sea holly [25]. Cumin seeds contain numerous phytochemicals that are known to have antioxidant, carminative and antiflatulent properties. The seeds are an excellent source of dietary fiber [26, 27]. Cumin is popular as culinary spice and used in folklore therapy because the presence of aromatic substances in the herb. Cumin comes under the category of traditional spice from middle ages. It was too much popular, because of its peppery flavor [28].

In traditional medicines, cumin was a major component of curry and chili powder that was used to flavor a variety of commercial food products. Cumin has also been crushed and mixed with foods such as fish and meat, and the seeds sprinkled on bread and cakes. The oil, derived by steam distillation, is used to flavor alcoholic beverages, desserts, and condiments. It is also used as a fragrant component of creams, lotions, and perfumes. Cumin has been used as antiinflammatory, diuretic, carminative, and antispasmodic, treatment of toothaches and epilepsy and also as an aid for treating dyspepsia, jaundice, diarrhea, flatulence, and indigestion [29]. Cumin is an aromatic herb and an astringent that benefits the digestive apparatus. It has been used in the 
treatment of mild digestive disorders as a carminative and eupeptic, as and astringent in bronco pulmonary disorders and as a cough remedy, as well as an analgesic [30]. The essential oil of cumin seeds has shown a significant antibacterial activity against $\mathrm{K}$. pneumoniae in vitro [31].

The most important chemical component of cumin fruits is essential oil content, ranging from $2.5 \%$ to $4.5 \%$ which is pale to colorless depending on age and regional variations. Studies of the chemical composition of cumin oil from different countries showed the presence of the following components: $\alpha$-pinene $(0.5 \%)$, Myrcene $(0.3 \%)$, limonene (0.5\%), 1-8-cineole $(0.2 \%)$, p-menth-3-en-7ol (0.7\%), pmentha-1, 3-dien-7-ol (5.6\%), caryophyllene $(0.8 \%), \beta$ bisabolene $(0.9 \%), \beta$-pinene $(13.0 \%)$, P-cymene $(8.5 \%), \beta$ phellandrene $(0.3 \%)$, D-terpinene $(29.5 \%)$, cuminic aldehyde (32.4\%), cuminyl alcohol (2.8\%), $\beta$-farnesene (1.1\%) together with much smaller quantities of $\alpha$-phellandrene, aterpinene, cis and trans sabinene, Myrtenol, $\alpha$-terpineol and phellandral. In addition to volatile oil cumin also contains nonvolatile chemical components including tannins, oleoresin, mucilage, gum, protein compounds and malates [32].

The cumin seeds contain aldehyde (60\%) fats, amino acids, flavonoids and glycosides $(22 \%)$, volatile oil $(2-5 \%)$ and the yellow colored fresh oil contains cuminaldehyde as its chief component [33]. The cumin fruit contains resin, fatty matter, gum, lignin, protein bodies and salts, largely composed of malates, extractive, and volatile oil. After the separation, a plenty number of phenolic compounds are identified in cumin fruits that includes phenolic acids, flavonoids, phenolic diterpenes, that are closely associated with their antioxidant activity and play an important role in inhibiting lipid peroxidation and various types of oxidizing enzymes [34]. The essential oil of cumin contains high levels of phenolic compounds, mainly cumin aldehyde, and paracymene. The antioxidant activity of b-pinene, p-cymene, gterpinene, cuminaldehyde and cumin oils [35]. The two standard active constituent of cumin such as cuminaldehyde and para-cymene have used to protect liver against oxidative stress and disease by increases the enzyme activities and malondialdehyde. Cuminaldehyde (4 - isopropyl benzaldehyde) is an aromatic monoterpenoid volatile compound [36].

The cumin oils have high antioxidant activity due to presence of monoterpene alcohols, essential flavours, flavonoids and other poly-phenolic molecules. Cumin oils have high antioxidant activity due to presence of monoterpene alcohols, essential flavours, flavonoids and other poly-phenolic molecules [37]. Recent studies have revealed that cumin seeds might also have anti-carcinogenic properties. In laboratory tests, this powerful little seed was shown to reduce the risk of stomach and liver tumors in animals. The detoxification and chemo-preventive properties accelerates secretion of anti-carcinogenic enzymes from the glands. It has antioxidants like Vitamin-C and Vitamin-A in it. It is particularly good for cancer of colon. Other antioxidants like Eugenol and limonene present in Cumin have strong anti-tumor properties. Recent research has revealed that cumin may slow the growth of breast and colon cancer cells [38].

Cumin is a traditional and herbal plant that has various useful and curable effects but it also has some side effects. Side effects of cumin include contact dermatitis (skin rash from contact with an allergen or irritant), respiratory reactions, and liver cancer (above dietary levels), and lower blood sugar levels and also increase the risk of bleeding [39]. A patient who suffers from ulcer and liver problems and also in women who are pregnant or breast feeding, they should have to use cumcaution. Patients should also have to use cumin with caution who taking agents that affect the immune system, antibiotics, anticancer drugs, anti-fungal, antiinflammatory agents, antioxidants, anti-seizure agents, cholesterol lowering and lipid lowering agents, estrogens, gastrointestinal agents, insecticides, iron, morphine, opioids, osteoporosis agents, painkillers, and phytoestrogens [40].

\section{Methods}

\subsection{Preparation of Samples}

\subsubsection{Cumin Oil}

The dried sample of cumin fruits were purchased from the local market of Shendi in the Rive Nile state, from season harvest 2016 - 2017. The sample was purified and then was subjected to distillation process via water - steam distillation method in which the water was heated, the steam was passed through the cumin fruits and vaporized the volatile compounds. The vapors were flowed through a coil, where they condensed back to liquid, which then was collected in the receiving vessel. At the end of the distillation process cumin oil was separated from water depending on the difference in their density by using laboratory separating funnel and kept at suitable temperature in dark pure bottle.

\subsubsection{Edible Oil Samples and Mixtures}

The sunflower oil was purchase from Shendi locality market. Four samples from this oil were prepared in equal volumes $(10 \mathrm{ml})$. In addition two samples of fried sunflower oil, (fish and taameia) were filtered and prepared in same volume. Tow samples were contained pure sunflower oil and one of two was subjected to heating process. To reminder (4 samples) $2 \mathrm{ml}$ of cumin oil were added and one of them which contain modern sunflower oil was heated after addition of cumin oil.

\subsection{Determination of Chemical Properties}

\subsubsection{Determination of Acid Value [12]}

Principle:

The acid value is determined by directly titrate the oil/fat in an alcoholic medium against standard potassium hydroxide/sodium hydroxide solution. The value is a measure of the amount of fatty acids which have been liberated by hydrolysis from the glycerides due to the action of moisture, temperature and/or lypolytic enzyme lipase. 


\section{Procedure:}

Two gram of cooled sample was weighed accurately in a $250 \mathrm{ml}$ conical flask and then $100 \mathrm{ml}$ of freshly neutralised hot ethyl alcohol and about one $\mathrm{ml}$ of phenolphthalein indicator solution were added. The mixture was boiled for about five minutes and titrated while hot against standard sodium hydroxide solution was shaking vigorously during the titration.

\section{Calculation:}

Acid value $=56.1 \mathrm{VN} / \mathrm{W}$

Where,

$\mathrm{V}=$ Volume in $\mathrm{ml}$ of standard potassium hydroxide or sodium hydroxide used.

$\mathrm{N}=$ Normality of the potassium hydroxide solution or Sodium hydroxide solution.

$\mathrm{W}=$ Weight in $\mathrm{g}$ of the sample.

\subsubsection{Determination of Saponification Value [12]}

\section{Principle:}

The oil sample is saponified by refluxing with a known excess of alcoholic potassium hydroxide solution. The alkali required for saponification is determined by titration of the excess potassium hydroxide with standard hydrochloric acid.

Procedure:

The sample was filtered through a filter paper to remove any impurities and the last traces of moisture until sure that the sample is completely had been dried. The sample mixed thoroughly and then $2.0 \mathrm{~g}$ of dry sample was weighed into a $250 \mathrm{ml}$ Erlenmeyer flask. $25 \mathrm{ml}$ of the alcoholic potassium hydroxide solution was pipette into the flask. A blank determination conducted along with the sample. The sample flasks and the blank flask was connected with air condensers, kept on the water bath, boiled gently but steadily until saponification was completed, as indicated by absence of any oily matter and appearance of clear solution. Clarity was achieved within one hour of boiling. After the flask and condenser had cooled somewhat washed down the inside of the condenser with about $10 \mathrm{ml}$ of hot ethyl alcohol neutral to phenolphthalein. The excess potassium hydroxide was titrated with $0.5 \mathrm{~N}$ hydrochloric acid, using about $1.0 \mathrm{ml}$ phenolphthalein indicator.

Calculation:

Saponification Value $=56.1(\mathrm{~B}-\mathrm{S}) \mathrm{N} / \mathrm{W}$
Where,

$\mathrm{B}=$ Volume in $\mathrm{ml}$ of standard hydrochloric acid required for the blank.

$\mathrm{S}=$ Volume in $\mathrm{ml}$ of standard hydrochloric acid required for the sample

$\mathrm{N}=$ Normality of the standard hydrochloric acid.

$\mathrm{W}=$ Weight in gm of the oil/fat taken for the test.

\subsubsection{Determination of Peroxide Value [45]}

\section{Principle of reaction:}

$\mathrm{PV}$ is a redox titrimetric determination. The assumption is made that the compounds reacting under the condition of the test are peroxides or similar product of lipid oxidation. Addition of excess potassium iodide reacts with the peroxide, iodine is produce. Through titration process, iodide reacts with standardized sodium thiosulfate using a starch indicator (Budavari, 1996).

$$
\begin{aligned}
& \mathrm{ROOH}+\mathrm{KI} \stackrel{H^{+}, \text {heat }}{\longrightarrow} \mathrm{ROH}+\mathrm{KOH}+\mathrm{I}_{2} \\
& \mathrm{I}_{2}+\operatorname{starch}(\text { blue })+2 \mathrm{Na}_{2} \mathrm{~S}_{2} \mathrm{O}_{3} \rightarrow 2 \mathrm{NaI}+\mathrm{Na}_{2} \mathrm{~S}_{4} \mathrm{O}_{6}+\text { starch } \\
& \text { (colorless) }
\end{aligned}
$$

Procedure:

$5.00 \mathrm{~g}$ of oil was dissolved with $30 \mathrm{ml}$ acetic acid and chloroform then $0.5 \mathrm{ml}$ saturated KI solution and $30 \mathrm{ml}$ distilled water were added. The mixture was titrated with $0.1 \mathrm{~N} \mathrm{Na} 2 \mathrm{~S} 2 \mathrm{O} 3$ until yellow is almost gone. $0.5 \mathrm{ml} 1 \%$ starch solution was added and titration continued until the light blue colour discharged.

Calculation:

Peroxide value $=$ S x N x 1000/g sample,

Where,

$\mathrm{S}=\mathrm{ml}$ of $\mathrm{Na}_{2} \mathrm{~S}_{2} \mathrm{O}_{3}$ (blank corrected)

$\mathrm{N}=$ normality of $\mathrm{Na}_{2} \mathrm{~S}_{2} \mathrm{O}_{3}$ solution.

\section{Results and Discussion}

\subsection{Results}

Fresh sunflower oil sample, fried fish oil and fried taameia oil $(\mathrm{T})$ were tested to determine the three chemical properties

\begin{tabular}{|c|c|c|c|c|c|c|}
\hline Oil sample & $\mathbf{P} \mathbf{V}$ & & AV & & SV & \\
\hline \multirow{2}{*}{ Fresh Sun flower oil } & Before & After & Before & After & Before & After \\
\hline & 7.3 & 2.7 & 0.94 & 0.17 & 184.60 & 190.65 \\
\hline Fried Taameia oil & 23 & 12.4 & 0.45 & 0.23 & 183.13 & 180.43 \\
\hline Fried Fish oil & 28 & 15.4 & 0.56 & 0.28 & 187.28 & 184.51 \\
\hline
\end{tabular}
before and after addition of cumin oil, table 1 explains that.

Table 1. Chemical properties of pure and frying oils before and after addition.

Then six samples of sun flower oil were prepares as following; pure $(\mathrm{P})$, pure + heat $(\mathrm{P}+\mathrm{H})$, pure + cumin oil $(\mathrm{P}+\mathrm{C})$, pure + cumin oil + heat $(\mathrm{P}+\mathrm{C}+\mathrm{H})$, frying fish oil + cumin oil $(\mathrm{F}+\mathrm{C})$ and frying taameia oil + cumin oil $(\mathrm{T}+\mathrm{C})$ in equal size $(10 \mathrm{ml})$ with $2 \mathrm{ml}$ cumin oil addition, after that samples were subjected to storage process similar to that in the Shendi market environment. The storage period was prolonged for six month, then samples were analyzed to assess their peroxide, acid and saponification value, table 2 and following figures represented that. 
Table 2. Effect of storage on the chemical properties of fresh sun flower oil.

\begin{tabular}{lll}
\hline Property & At the beginning & After storage \\
\hline Peroxide value & 7.3 & 18.17 \\
Acid value & 0.94 & 4.3 \\
Saponification value & 184.06 & 196.39 \\
\hline
\end{tabular}

Table 3. Effect of cumin oil and heat on the chemical properties of six storage samples.

\begin{tabular}{llll}
\hline Sample & PV & AV & SV \\
\hline Pure & 18.17 & 4.32 & 198.43 \\
P + H & 11.59 & 2.16 & 196.39 \\
P + C & 9.22 & 1.37 & 190.61 \\
P + C + H & 7.93 & 1.1 & 189.54 \\
F + C & 13.22 & 2.48 & 193.35 \\
T + C & 11.39 & 1.84 & 189.07 \\
\hline
\end{tabular}

\section{Peroxide value}

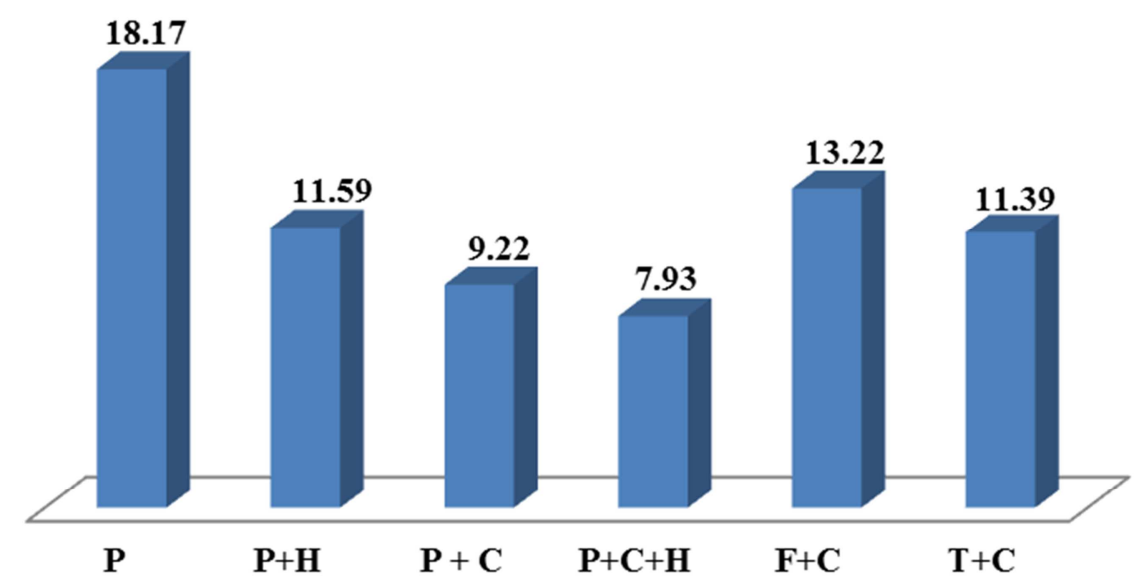

Figure 1. Peroxide value of six storage samples.

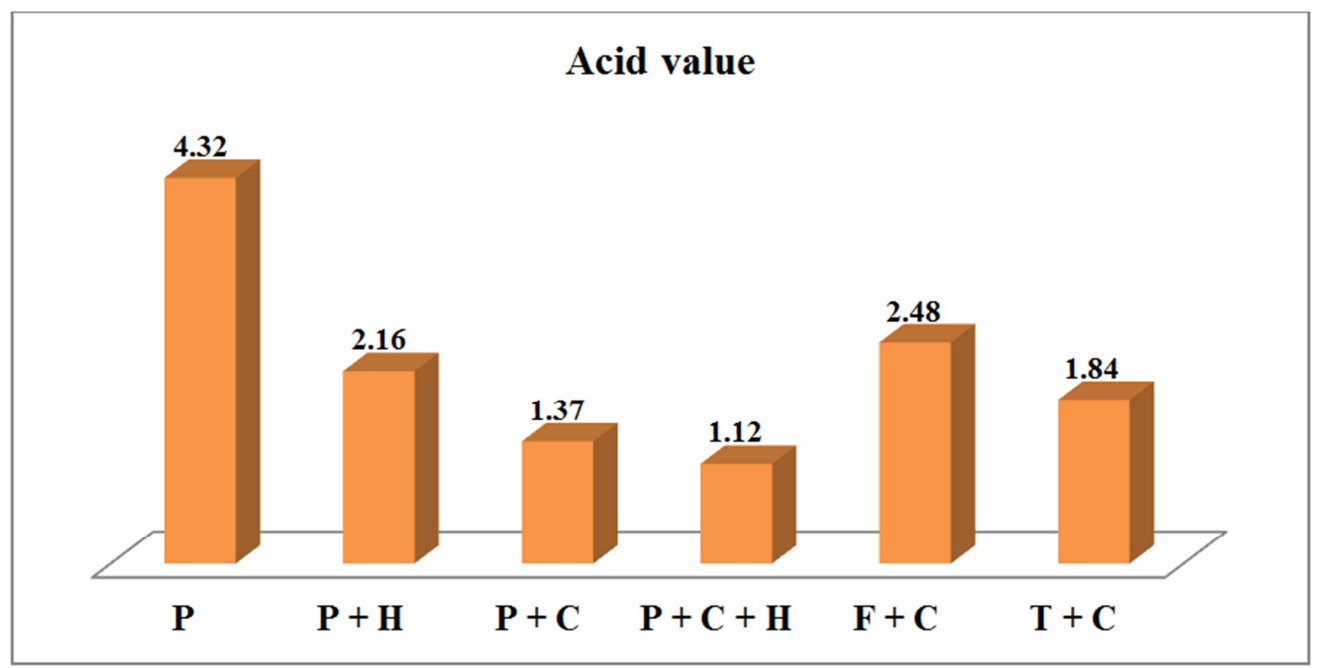

Figure 2. Acid value of six storage samples. 


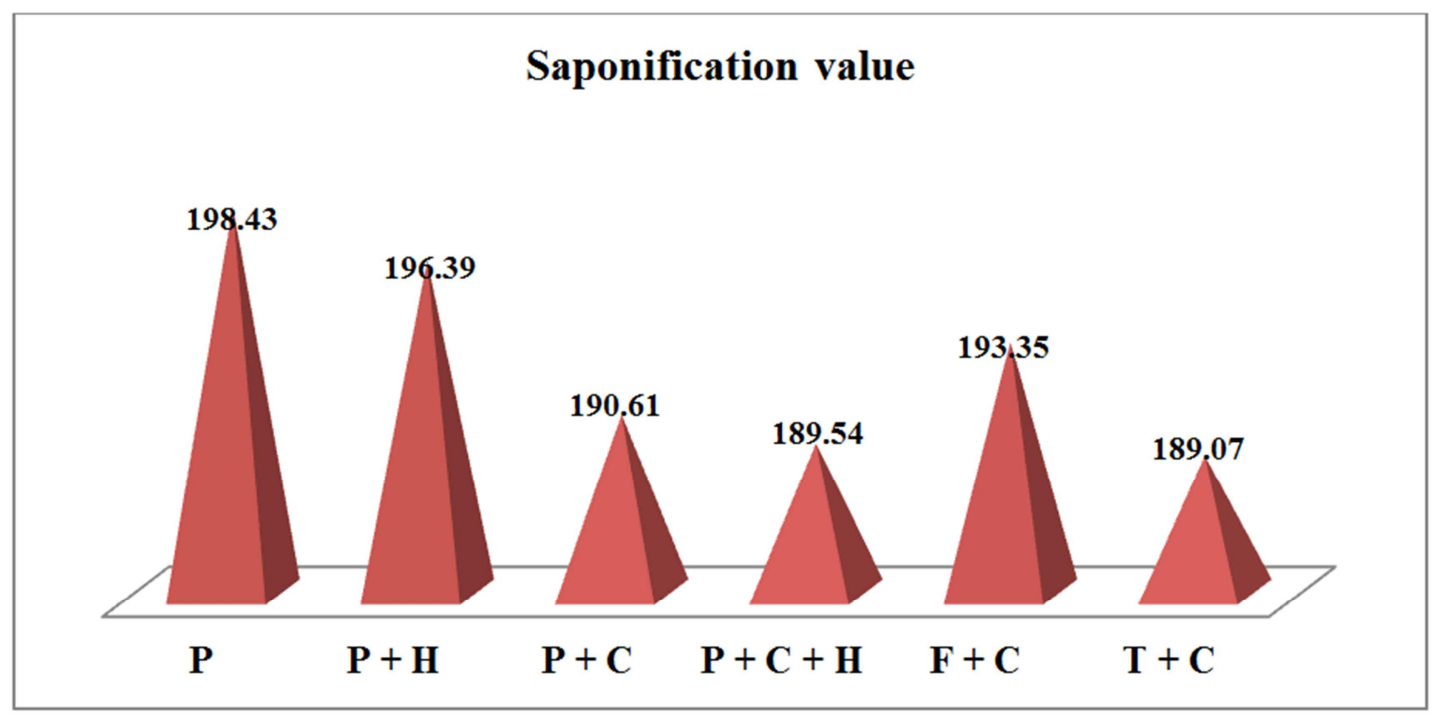

Figure 3. Saponification value of six storage samples.

The following figures show separately the peroxide, acid and saponification property from the beginning period (before and after addition of cumin oil) and at the end storage period.

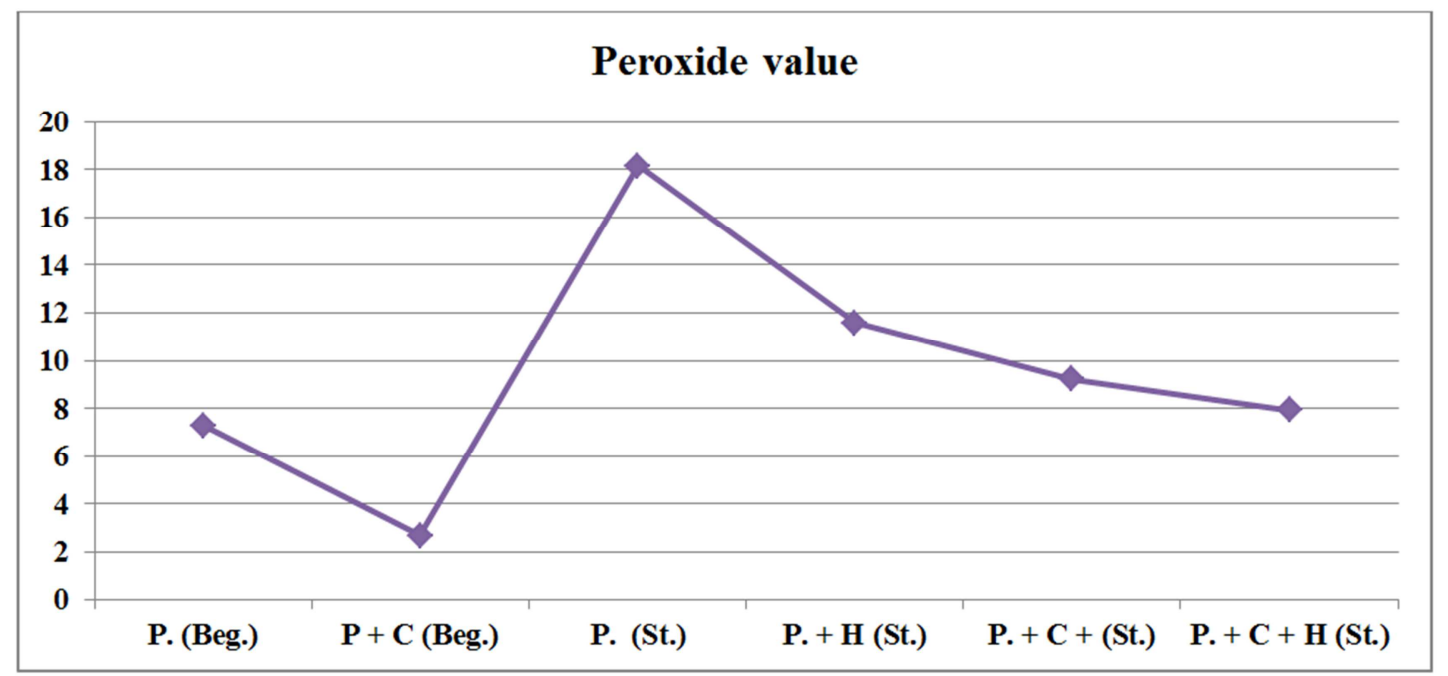

Figure 4. Peroxide value from the beginning to the end storage.

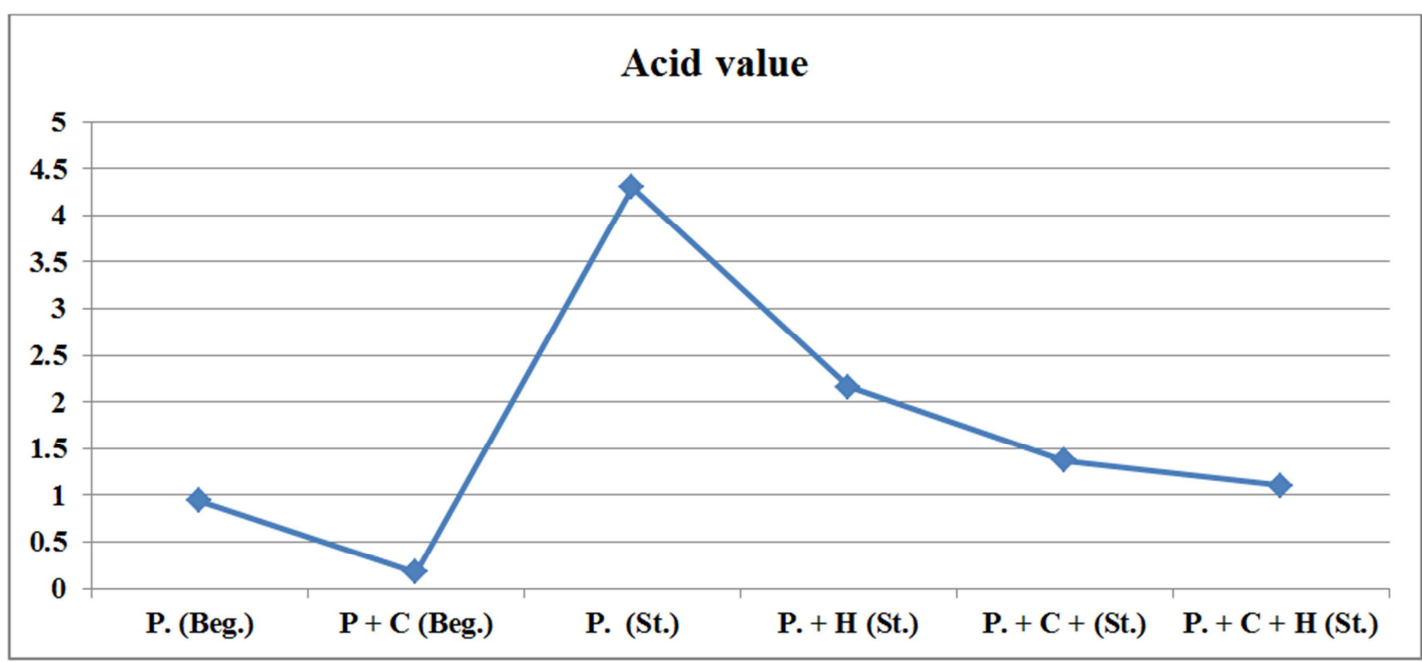

Figure 5. Acid value from the beginning to the end storage. 


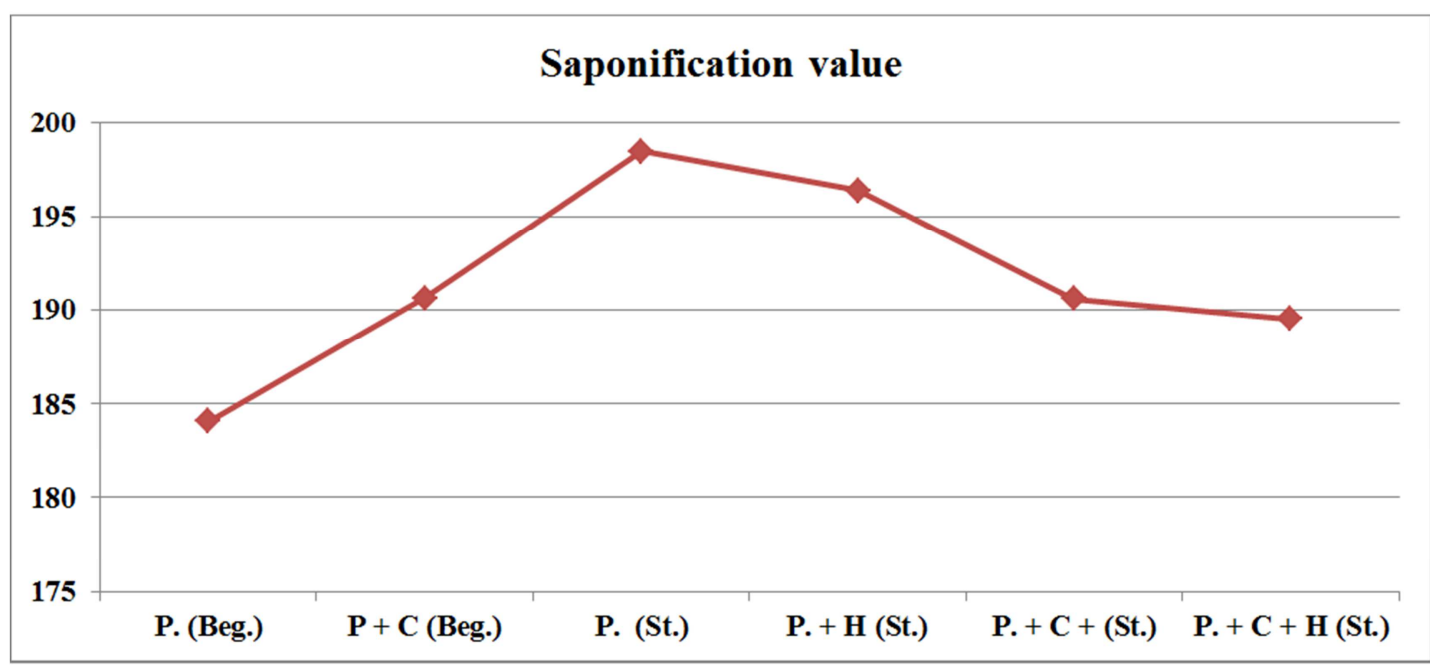

Figure 6. Saponification value from the beginning to the end storage.

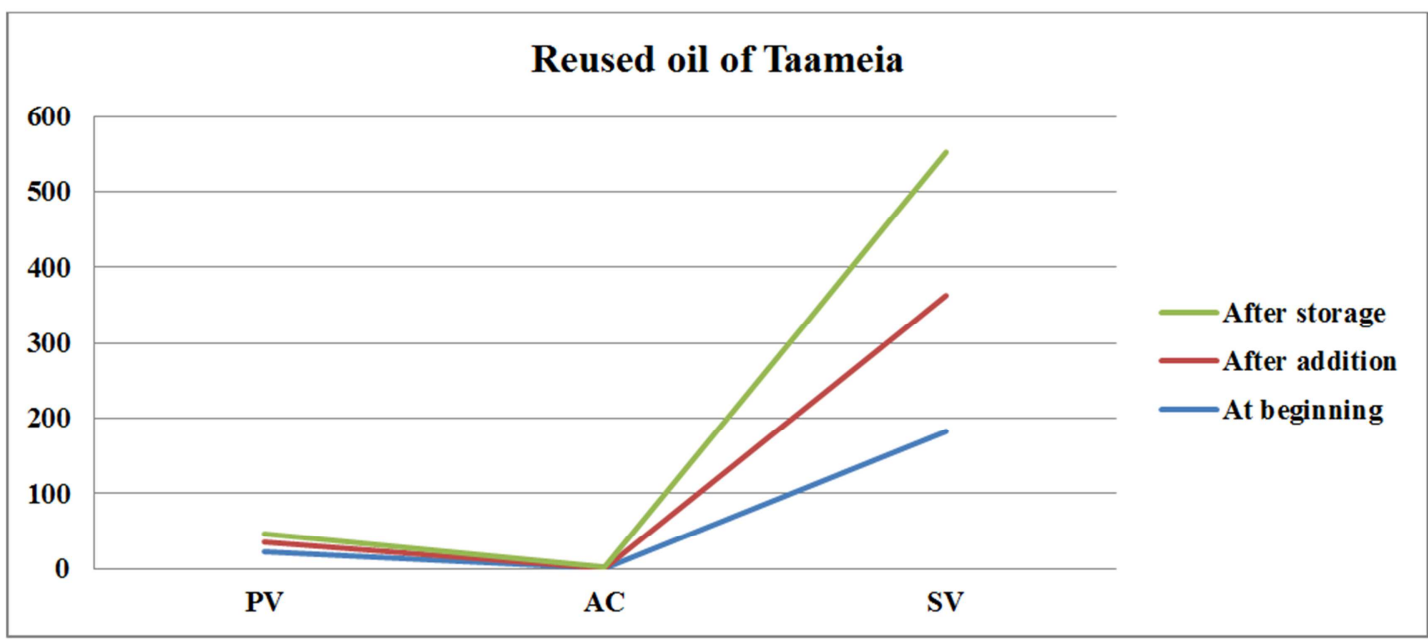

Figure 7. Chemical properties of fried taameia oil.

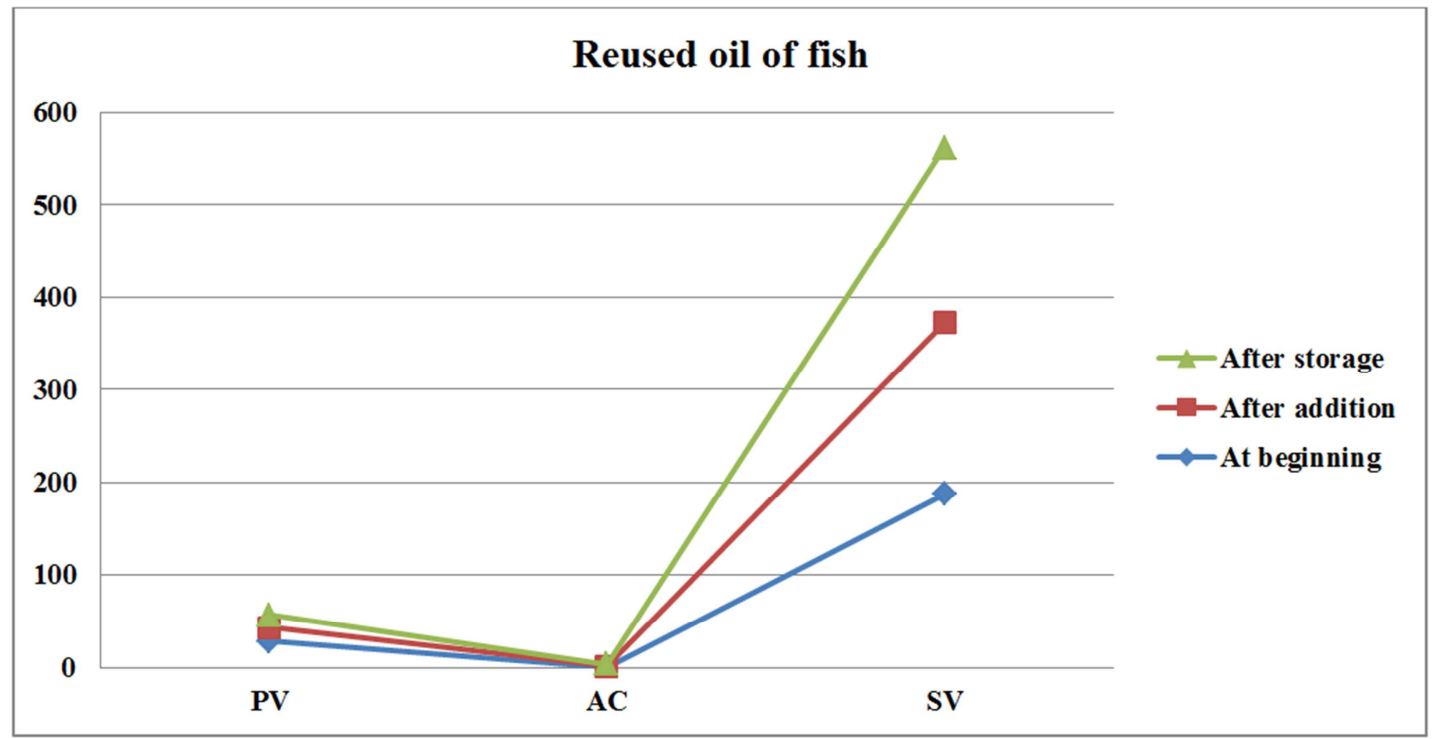

Figure 8. Chemical properties of fried fish oil.

Table 1 shows the chemical properties of three samples of pure Sunflower oil and two samples of fried oil (taameia and fish). The peroxide value decreased when adding cumin oil; from $(7.3$ - 2.7), (23 - 12.4) and (28 - 15.4) for pure 
sunflower oil and fried oils respectively, the result could be attributed to antioxidant that were presented in cumin oil such as terpenes, aldehyde, alcohol and phenolic compounds. Also, there was decrease in the acid value after the addition of cumin oil in the three samples $(0.94-0.17),(0.45-0.23)$ and $(0.56-0.28)$ respectively, that can be due to the reaction between chemical constituents of cumin and sample oil which lead to decline carboxyl groups in oil. While for saponification, there was an increase in pure sample $(184.60$ - 190.65) could be due to increase of ester formation result from previous reactions. In contrast, there was a decrease in fried oils (183.13 - 180.43) and (187.28 - 184.51) for taameia and fish. This could be explained as the high oxidation caused by food frying and then cooling, as well as the oils of taameia and fish itself which with frying process lead to more ester formation, consequently raised the saponification value.

The effect of storage is clearly evident on the three chemical properties of the pure oil sample, Table 2, where we showed the apparent increase in the three values (7.3-18.17), $(0.95-4.3)$ and $(184.06$ - 196.39) for peroxide, acid and saponification values respectively, that was indicated to oxidation process occurred, which may be caused by oxygen and light, they worked to oxidize the fatty acids found in the oil and converted it to the peroxides, carbonyl and carboxylic compounds.

The influence of cumin on the chemical properties of edible oil was revealed in the value of peroxide, which led to a decrease in its value from 7.3 to 2.7 after adding it at the beginning of storage and its effect was very clear after the completion of the storage process. The peroxide value of pure edible oil was 18.17 , while for the mixture of the same sample of edible oil and cumin became 9.22, this clearly reflects the effect of cumin oil as an antioxidant that because it contains the antioxidant compounds. With reference to Tables 1 and 3, the study showed that the addition of cumin oil had a positive effect on the peroxide value of cooking oils. The value of peroxide was reduced when adding cumin oil to sunflower oil at the beginning of storage from 23 to 12.4 for fried taameia oil and 28 to 15.4 for fried fish oil. More lower was observed after adding cumin oil with storage where it reached 11.39 and 13.2 for the fried oil respectively.

On the other hand the study showed that the temperature had revealed unexpected effect on the peroxide value, where it was expected to increase the oxidation process and then elevated peroxide value, but it has reduced the value of peroxide where the value of peroxide of stored oil was 18.17 while the oil was stored after boiling 11.59. Also the effect was more pronounced when cumin oil was added with storage, which was dropped to 7.93 compared to the addition of cumin oil with non-boiling. This difference in the value of peroxide produced by a temperature variation can be attributed to the fact that the boiling temperature accelerates the antioxidant reactions between the sunflower oil and cumin oil, thereby reducing oxidative compounds and thus reducing the value of peroxide.

\section{Conclusion and Recommendations}

The overall evaluation of this study concludes the importance of cumin oil as an oxidative material. This was evident in the low peroxide value of fresh and fried edible oil, which is considered the most important characteristic of oxidation. These results were obtained when measuring the value of peroxide before and after the addition of cumin oil and at the end of storage period. These investigations resulted in a clear reduction in the peroxide value of the mixtures oil compared with pure sunflower oil. Unexpectedly for the temperature, the boiling of fresh and mixture oil before storage had appeared a decrease in peroxide value. This study opens up a wide field to other studies to emphasize these results as well as taking advantage of the oxidative properties of cumin oil in the conservation of edible oils for longer periods with the possibility of utilization of cooking oils after reducing the peroxide value in other industries.

\section{References}

[1] Marina, A. M., Wan Rosli, W. I., Noorhidayah, M., 2013. Quantitative Analysis of Peroxide Value in Virgin Coconut Oil by ATRFTIR Spectroscopy, TheOpen Conference Proceedings Journal 4, (Suppl-2, M13) 53-56.

[2] Lupea, A. X., 2004. Transformări ale biocompuşilor procesaţi în scop alimentar, Editura CEPUSM, Chișinău, 26-72.

[3] Guillen M. D., Cabo N. (2002). Fourier transform infrared spectra datd versus peroxide and anisideine values to determine oxidative stability of edible oils. Food Chem 77:503-10.

[4] Silva F. M., Borges F., Ferreria M. A. (2001). Effects of phenolic propyl esters on the oxidative stability of refined sunflower oil. J. Agric. Food Chem. 49:3936-41.

[5] Hmilton R. J. (1994). The chemistry of rancidity in foods. In: Allen J. C., Hamilton R. J. editors. Rancidity in foods. $3^{\text {rd }}$ ed. London: Blakle academic\& professional. P 1-21.

[6] Halliwell B (1995). Antioxidant characterization. Methodology and mechanism. Biochem Pharmacol, 49: 13411348 .

[7] Frankel EN and Meyer AS (2000). The problems of using one-dimensional methods to evaluate multifunctional food and biological antioxidants. Journal of the Science of Food and Agriculture, 80: 1925-1941.

[8] Saha D and Tamrakar A (2011). Xenobiotics, oxidative stress, free radicals vs. antioxidants: dance of death to heaven's life. Asian Journal of Research in Pharmacology Science, 1: 36.

[9] Stuckey BN (1980). Hand book of food additives: CRC Press Boca Raton FL.

[10] Abramovic, H., Abram, V., 2005. Physico-Chemical Properties, Composition and Oxidative Stability of Camelina sativa Oil, Food Technol. Biotechnol., 43 (1), 63-70.

[11] Choe, E., Ming B. D., 2006. Mechanisms and factors for edible oil oxidation. Comp. Rev. Food Sci. Food Safety, 5 (4): 169-186. 
[12] CODEX-STAN 210 - 1999. Standard for Named Vegetable Oils.

[13] Kirk, R. and Sawyer R. 1991. Pearson's composition and analysis of foods. 9th edition, Addison Wesley longman ltd. England. pp. 9- 29, 608-640.

[14] Kapila, N., Seneviratne and D. M. S., Dissanayake, 2005. Effect of Method of Extraction on the Quality of Coconut oil. J. Sci. Univ., Kelaniya 2: 63-72.

[15] Abayeh, O. J., Aina, E. A. and Okuonghae, C. O. 1998. Oil content and oil quality characteristics of some Nigerian oil seeds. J. Pure and Applied Sci. 1: 17-23.

[16] Asiedu, J. J. 1989. Processing Tropical Crops. A Technological Approach. MacMillan Publishers, London, pp. 170172, 226-246.

[17] Manual of methods of analysis of food, oils and fats (Lab manual 2). (2015). Food safety and standards authority of India ministry of health and family Welfare government of India New Delhi, P: 21-27.

[18] Pearson, D. (2008). 'Chemical analysis of food', Cornell University.

[19] Henry, L. N. (2016). Effect of Light and Air on the Quality and Stability of Selected Vegetable Oils. International Journal of Innovative Research in Science, Engineering and Technology. Vol. 5, Issue 5. P: $6609-16$.

[20] Science daily, 'Toxic Substances in Oxidation of Fats and Oil'. United Kingdom, 2005.

[21] Srivastava KC. Extracts from Two Frequently Consumed Spices- Cumin (Cuminurn cyminum) and Turmeric (Curcuma longa) - inhibit platelet aggregation and alter eicosanoid biosynthesis in human blood platelets. Prostaglandins Leukotnenes and Essential Fatty Acids 1989; 137: 57-64.

[22] Nazeeem, P. A. 1995. The spices of India. The Herb, Spice, and Medicinal Plant Digest 13(1): 1-5.

[23] Raghavan, S. 2007. Handbook of spices, seasonings, and flavorings. 2nd Ed. CRC Press, Taylor \& Francis Group, Boca Raton.

[24] Peter, K. V. 2001. Handbook of herbs and spices Vol. 1. Woodhead Publishing Limited Abington Hall, Abington Cambridge, England.

[25] Jirovetz L, Buchbauer G, Stoyanova AS, Georgiev EV, Damianova ST. Composition, quality control and antimicrobial activity of the essential oil of cumin (Cuminum cyminum L.) seeds from Bulgaria that had been stored for up to 36 years. International Journal of Food Science and Technology 2005; 40: 305-310.

[26] Johri RK. Cuminum cyminum and Carum carvi: An update. Pharmacogn Rev 2011; 5(9): 63-72. 59.

[27] Al-Hashemi FHY. Chromatographic separation and identification of some volatile oils, organic acids and phenols from the seeds of cuminum cyminum growing in Iraq. IJRRAS 2014; 19(1): 80-90.
[28] Rebey IB, Jabri-Karoui I, Hamrouni-Sellami I, Bourgou S, Limam F, Marzouk B. Effect of drought on the biochemical composition and antioxidant activities of cumin (Cuminum cyminum L.) seeds. Industrial Crops and Products 2012; 36: $238-245$.

[29] Hanif C, Ayesha T, Adila S, Saeed M, Tanveer A, Ashfaq M. Physico-chemical investigation and antimicrobial activity of essential oil of Cuminum cyminum L. World applied Sciences Journal. 2012; 19(3): 330-333.

[30] De M, De AK, Mukhopadhvay R, Banerjee AB, Micro M. Antimicrobial activity of Cuminum cyminum L. Ars Pharmaceutica 2003; 44: 257-69.

[31] Derakhshan S, Sattari M, Bigdeli M. Effect of subinhibitory concentrations of cumin (Cuminum cyminum L.) seed essential oil and alcoholic extract on the morphology, capsule expression and urease activity of Klebsiella pneumoniae. Int J Antimicrob Agents 2008; 32: 432-436.

[32] Nadeem M and Riaz A (2012). Cumin (Cuminum cyminum) as a potential source of antioxidants. PAK. J. FOOD SCI., 22(2), 2012:101-107.

[33] Iacobellis NS, Cantore PL, Capasso F, Senatore F. Antibacterial activity of Cuminum cyminum L. and Carum carvi L. essential oils. J Agric Food Chem 2005; 53: 57-61. 48.

[34] Gallo M, Ferracane R, Giulia G, Ritieni A, Fagliano V. Microwave assisted extraction of phenolic compounds from four different spices. Molecules 2010; 15(3): 6366-6374.

[35] Goto T, Takahashi N, Hirai S, Kawada T. Various terpenoids derived from herbal and dietary plants function as PPAR modulators and regulate carbohydrate and lipid metabolism. PPAR research 2010; 1-9.

[36] Kunzemann J, Herrmann K. Isolation and identification of flavon (ol)-o-glycosides in caraway (Carum carvi L.), fennel (Foeniculum vulgare Mill.), anise (Pimpinella anisum L.), and coriander (Coriandrum sativum L.), and of flavon-Cglycosides in anise. I. Phenolics of spices (author's transl). Z Lebensm Unters Forsch 1977; 164(3):194-200.

[37] Rodov V, Vinokur Y, Gogia N, Chkhikvishvili I. Hydrophilic and lipophilic antioxidant capacities of Georgian spices for meat and their possible health implications.

[38] Paradise India (2010) Wonders of Cumin. Volume 1 Issue 5; 2-3.

[39] [Lee HS. Cuminaldehyde: aldose reductase and $\alpha$-glucosidase inhibitor derived from Cuminum cyminum L. seeds. Journal of agricultural and food chemistry 2005; 53: 2446-50.

[40] Morshedi D, Aliakbari F. The inhibitory effects of cuminaldehyde on amyloid fibrillation and cytotoxicity of alpha-synuclein. Modares Journal of Medical Sciences: Pathobiology 2012; 15: 45-60.

[41] AOAC Official Method 965.33 Peroxid Value of Oils and Fats. Titration Method. 